\title{
Tip-enhanced Raman mapping of single-walled carbon nanotube networks in conductive composite materials
}

\section{Citation for published version (APA):}

Hoffmann, G. G., Bârsan, O. A., van der Ven, L. G. J., \& de With, G. (2017). Tip-enhanced Raman mapping of single-walled carbon nanotube networks in conductive composite materials. Journal of Raman Spectroscopy, 48(2), 191-196. https://doi.org/10.1002/jrs.5004

\section{Document license:}

TAVERNE

DOI:

10.1002/jrs.5004

Document status and date:

Published: 02/02/2017

\section{Document Version:}

Publisher's PDF, also known as Version of Record (includes final page, issue and volume numbers)

\section{Please check the document version of this publication:}

- A submitted manuscript is the version of the article upon submission and before peer-review. There can be important differences between the submitted version and the official published version of record. People interested in the research are advised to contact the author for the final version of the publication, or visit the $\mathrm{DOI}$ to the publisher's website.

- The final author version and the galley proof are versions of the publication after peer review.

- The final published version features the final layout of the paper including the volume, issue and page numbers.

Link to publication

\section{General rights}

Copyright and moral rights for the publications made accessible in the public portal are retained by the authors and/or other copyright owners and it is a condition of accessing publications that users recognise and abide by the legal requirements associated with these rights.

- Users may download and print one copy of any publication from the public portal for the purpose of private study or research.

- You may not further distribute the material or use it for any profit-making activity or commercial gain

- You may freely distribute the URL identifying the publication in the public portal.

If the publication is distributed under the terms of Article 25fa of the Dutch Copyright Act, indicated by the "Taverne" license above, please follow below link for the End User Agreement:

www.tue.nl/taverne

Take down policy

If you believe that this document breaches copyright please contact us at:

openaccess@tue.nl

providing details and we will investigate your claim. 


\title{
Tip-enhanced Raman mapping of single-walled carbon nanotube networks in conductive composite materials
}

\author{
Günter G. Hoffmann, ${ }^{a, b *}$ Oana A. Bârsan, ${ }^{a, b}$ Leendert G. J. van der Ven $^{\text {a }}$ \\ and Gijsbertus de With ${ }^{\mathrm{a}}$
}

\begin{abstract}
Identifying and characterizing the structural integrity of single-walled carbon nanotubes (SWCNTs) that are fully embedded in a polymer matrix without causing any damage to them is a difficult task to achieve for bulk samples. Using tip-enhanced Raman spectroscopy, the surface of a polymer-embedded conductive network of SWCNTs was mapped underneath a thin layer of pure polymer. The technique was also used to detect tube-breaking within the composite sample caused by mechanical stress, beyond the 'visual' capabilities of scanning electron microscopy techniques. Results show that tip-enhanced Raman mapping can be used to successfully identify and characterize SWCNTs even underneath a layer of polymer. Copyright $\odot 2016$ John Wiley \& Sons, Ltd.
\end{abstract}

Keywords: tip-enhanced Raman spectroscopy (TERS); tip-enhanced Raman mapping (TERM); conductive composites; epoxy/amine systems; single-walled carbon nanotubes (SWCNTs)

\section{Introduction}

Electrically conductive composite materials form an area of very active research, as the industry is looking for a replacement of metals in data cables and light power cables, windings in electric motors, housings for shielding of electromagnetic radiation, and the prevention of the buildup of electrostatic charges, ${ }^{[1]}$ conductive composites based on polymers and carbon nanotubes (CNTs) are particularly promising materials. ${ }^{[2,3]}$ As the mechanical properties of those composites normally are also improved compared with the pure polymer, they can be used as lightweight materials in airplanes and spacecrafts. The added CNTs also increase the thermal conductivity of the polymer. However, despite many efforts, it is still difficult to combine CNTs with polymers, and the resulting composites generally contain large agglomerates of CNTs. ${ }^{[2,4]}$ Moreover, the resulting conductivities of the composites are still disappointingly low. In a previous study, we used a pre-formed CNT network that we impregnated under vacuum with an epoxy/amine polymer, and the resulting composite was peeled-off from a glass substrate to obtain a freestanding film (see Bârsan et al. ${ }^{[5]}$ ). The high electrical conductivity of the pre-formed network was maintained within the same order of magnitude, but resistance measurements taken at the bottom of the films showed a wide range of values obtained for the same sample, because of apparent composite inhomogeneity. But how do those networks look like after polymer impregnation? Are the CNTs structurally and chemically the same after polymer impregnation? Are the conductivity variations of the bulk material related to changes in the CNT structure? Electron microscopy is surely of help, but the contrast between the CNTs and the polymer (two carbon materials) is low once the CNTs are covered in polymer.

The key questions, as stated in these introductory lines, do have received so far insufficient attention to provide (semi-)definitive answers. In this paper, we present (the results of) a sophisticated tool for characterizing CNT composites - as such already a complex task - to provide, at least, partial answers.

Chemical identification and discrimination of the two materials forming the composites can be performed by the vibrational spectroscopic technique of Raman spectroscopy. In the case of singlewalled carbon nanotubes (SWCNTs), the technique can be used to measure the diameter of the tubes, to probe the orientation of the tubes using polarized radiation, and to study the interactions of tubes and polymers in composites. Spatial mapping of the chemical composition of the sample can be performed by confocal Raman mapping, giving a spatial resolution of about half the wavelength of the exciting laser used $(\sim 300 \mathrm{~nm}$ in our case). This resolution is not enough for our task of characterizing low diameter nanotubes inside a polymer matrix. Help comes from the relatively young method of measuring tip-enhanced Raman spectra while scanning the sample. The technique, with the first report published in 2000 by Stöckle et al. ${ }^{[6]}$ and developed during the last 15 years, allows for topological analysis and identification of the sample's components. It has been applied to $\mathrm{CNTs}_{1}{ }^{[7]}$ graphene, ${ }^{[8]}$ photovoltaics, ${ }^{[9]}$ catalysis, $^{[10]}$ semiconductors, ${ }^{[11]}$ polymers, ${ }^{[12]}$ and biological compounds such as membranes, ${ }^{[13]}$ nucleic acids, ${ }^{[14]}$

\footnotetext{
* Correspondence to: Günter G. Hoffmann, Laboratory of Materials and Interface Chemistry, Department of Chemical Engineering and Chemistry, Eindhoven University of Technology, Het Kranenveld 14, 5612 AZ Eindhoven, The Netherlands. E-mail: G.G.Hoffmann@tue.nl

a Laboratory of Materials and Interface Chemistry, Department of Chemical Engineering and Chemistry, Eindhoven University of Technology, Het Kranenveld 14, 5612 AZ, Eindhoven, The Netherlands
}

b Dutch Polymer Institute (DPI), P.O. Box 902, 5600 AX, Eindhoven, The Netherlands 
peptides $_{1}^{[15]}$ proteins, $^{[16]}$ mitochondria, ${ }^{[17]}$ and even whole viruses. ${ }^{[18]}$ It has been used to detect defects in nanotubes, to localize the edges of graphene sheets, and to measure strain in semiconductors. ${ }^{[19]}$ Compared with confocal Raman mapping, the spatial resolution of the technique is much higher, and the sensitivity is highly increased: While the lateral resolution increases from 300 to $20 \mathrm{~nm}$, the sampled area is reduced from $70000^{[2]}$ to $300 \mathrm{~nm},{ }^{[2]}$ and the Raman signal is amplified up to 250 times. That corresponds, taken the area into account, to an increase in sensitivity of up to 40000 times. We have used this technique to study the distribution of CNTs under a surface layer of polymer and their answer to mechanical stress.

\section{Experimental details}

\section{Tip preparation}

Tips were prepared via etching using an acid solution prepared by mixing absolute ethanol (p.A., Merck) and 37\% $\mathrm{HCl}$ (p.A., Merck) at a volume ratio of $1: 1$. A $99.999 \%$ gold wire (Alfa) of $200 \mu \mathrm{m}$ diameter was flame annealed before etching. Electrochemical etching with an applied voltage of $2.4 \mathrm{~V}$ (as described in the literature ${ }^{[20,21]}$ ) was used to prepare the tips. Cone-shaped gold tips, with a typical radius of $\sim 30 \mathrm{~nm}$, were obtained.

\section{Measurement}

Optical microscopy, tip-enhanced Raman spectroscopy (TERS), and tip-enhanced Raman mapping (TERM) measurements were carried out on the bottom of a peeled-off film without gold coating using an NTEGRA SPECTRA ('Nanofinder', NT-MDT, Russia). A HeNe laser with a wavelength of $632.8 \mathrm{~nm}$ was used as light source. Further particulars are given in the 'Results and Discussion' section and in our previous report. ${ }^{[20]}$ A typical lateral/depth resolution of about $20-30 \mathrm{~nm}$ is expected from these measurements. ${ }^{[22]}$

\section{Preparation of SWCNT networks}

All chemicals were used as received, without any further purification. Super high purity SWCNTs, manufactured by the chemical vapour deposition (CVD) method, were purchased from US Research Nanomaterials, Inc. A total of $0.1 \%$ dispersions of SWCNTs were prepared by adding $10 \mathrm{mg}$ SWCNTs as purchased and $300 \mathrm{mg}$ of sodium carboxymethyl cellulose (CMC), $90000 \mathrm{MW}\left(\mathrm{C}_{28} \mathrm{H}_{30} \mathrm{Na}_{8} \mathrm{O}_{27}\right)$, from Sigma Aldrich to $10 \mathrm{~mL}$ of distilled water. The dispersions were kept cool in an ice bath while being sonicated for 15 min using a SONICS Vibra-Cell sonicator with a $6.4 \mathrm{~mm}$ tip diameter and $60 \%$ of maximum amplitude (as described by Li et $a l^{[23]}$ ). The solution was then centrifuged at $8500 \mathrm{rpm}$ for $1 \mathrm{~h}$ in a $1.5-\mathrm{cm}$ diameter vessel, using a SIGMA 3-30 K centrifuge, and only the upper $80 \%$ of the supernatant was kept. The glass substrates were cleaned by immersion into an Radio Corporation of America (RCA) cleaning solution (five parts $\mathrm{H}_{2} \mathrm{O}$, one part $\mathrm{NH}_{4} \mathrm{OH}, 30 \%$, one part $\mathrm{H}_{2} \mathrm{O}_{2}, 30 \%$ ) without heating, left overnight, and then rinsed with distilled water. Thin films of SWCNTs and CMC were deposited on $7 \mathrm{~cm} \times 7 \mathrm{~cm}$ glass substrates with a $30 \mathrm{~mm}$ gap doctor blade at a speed of $10 \mathrm{~mm} \mathrm{~s}^{-1}$, using a COATMASTER $509 \mathrm{MC}$. The films were then dried for $20 \mathrm{~h}$ in an oven at $45^{\circ} \mathrm{C}$. The as-prepared samples were immersed into an acid bath $\left(\mathrm{HNO}_{3}, 9 \mathrm{M}\right)$ for $4 \mathrm{~h}$ at $40^{\circ} \mathrm{C}$ and thereafter taken out and dried at $45^{\circ} \mathrm{C}$ for $2 \mathrm{~h}$ under vacuum. The samples were subsequently kept for $20 \mathrm{~h}$ at $150^{\circ} \mathrm{C}$ under vacuum for acid residue removal, and for 2 hours at $400^{\circ} \mathrm{C}$ in a nitrogen atmosphere for
CMC residue removal, resulting in $\sim 40 \mathrm{~nm}$ thick films (e.g. ${ }^{[24]}$ ). Thermogravimetric analysis on pure CMC was performed using Q500 equipment, with a heating rate of $10^{\circ} \mathrm{C} \mathrm{min}^{-1}$ between 25 and $600^{\circ} \mathrm{C}$ both in air and nitrogen atmospheres.

\section{Polymer impregnation}

An epoxy/amine system was used as the polymer matrix. A bisphenol A-based epoxy resin (Epikote 828, Resolution Nederland BV) with an equivalent weight per epoxide group of $187 \mathrm{~g} \mathrm{~mol}^{-1}$ and Jeffamine D-230 (Huntsman Holland BV) with an $\mathrm{NH}$-equivalent weight of $60 \mathrm{~g} \mathrm{~mol}^{-1}$ was chosen as the model system. The polymer was prepared by mixing the two components at a $1: 1$ epoxy/amine ratio (based on an epoxy group/NH equivalent), using an RCT basic IKA magnetic stirrer for $5 \mathrm{~min}$ at $700 \mathrm{rpm}$, followed by 3 min degassing in a BRANSON 1510 ultrasonic cleaner. The mixture was then coated onto the SWCNT film using a $60 \mu \mathrm{m}$ gap doctor blade and cured in an oven at $100^{\circ} \mathrm{C}$ for $4 \mathrm{~h}$. A freestanding sample could be obtained by manually peeling the film off the glass substrate and measuring/imaging at the bottom side.

\section{Scanning electron microscopy}

Scanning electron microscope (SEM) images were taken with a Quanta 3D FEG microscope at the bottom of the peeled-off film, using an accelerating voltage of $10 \mathrm{kV}$. Some samples were sputtered with gold for enhanced contrast.

\section{Results and discussion}

For our study, we chose SWCNTs, as multi-walled carbon nanotubes would add more complications to our system and cause interpretation issues. The single SWCNTs have an average diameter of $1 \mathrm{~nm}$, as proven by the radial breathing mode (RBM) in their Raman spectrum, but they form bundles (ropes of aligned tubes), the thickness of which in the SEM images appears relatively large, as the sample was coated with Au to avoid charging, thereby deteriorating the image quality. Figure 1 shows a Raman spectrum of the pristine SWCNTs with a zoom-in for the RBM modes. From the relations for the RBM in their Raman spectrum known from literature $\omega_{\mathrm{RBM}}=A / d_{\mathrm{CNT}}+B$, where $A=234 \mathrm{~cm}^{-1} \mathrm{~nm}$ and $B=10 \mathrm{~cm}^{-1}$ are parameters determined experimentally for bundles of SWNTs (see Dresselhaus et al. ${ }^{[25]}$ ), we calculate the diameters of the tubes to range from 0.9 to $1.3 \mathrm{~nm}$, the main species having a diameter of $1.0 \mathrm{~nm}$, which is also the mean diameter. As the polymer

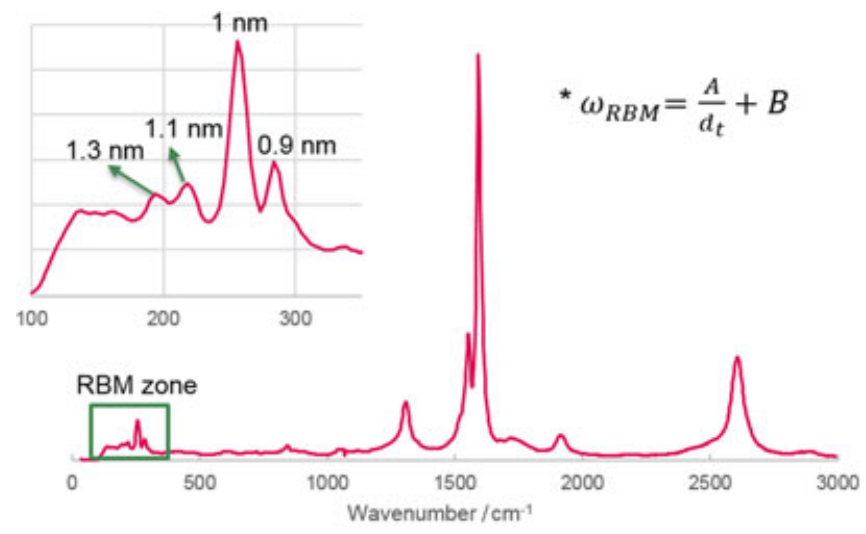

Figure 1. Calculation of the tube diameters using the radial breathing modes (RBMs) in the Raman spectrum. 


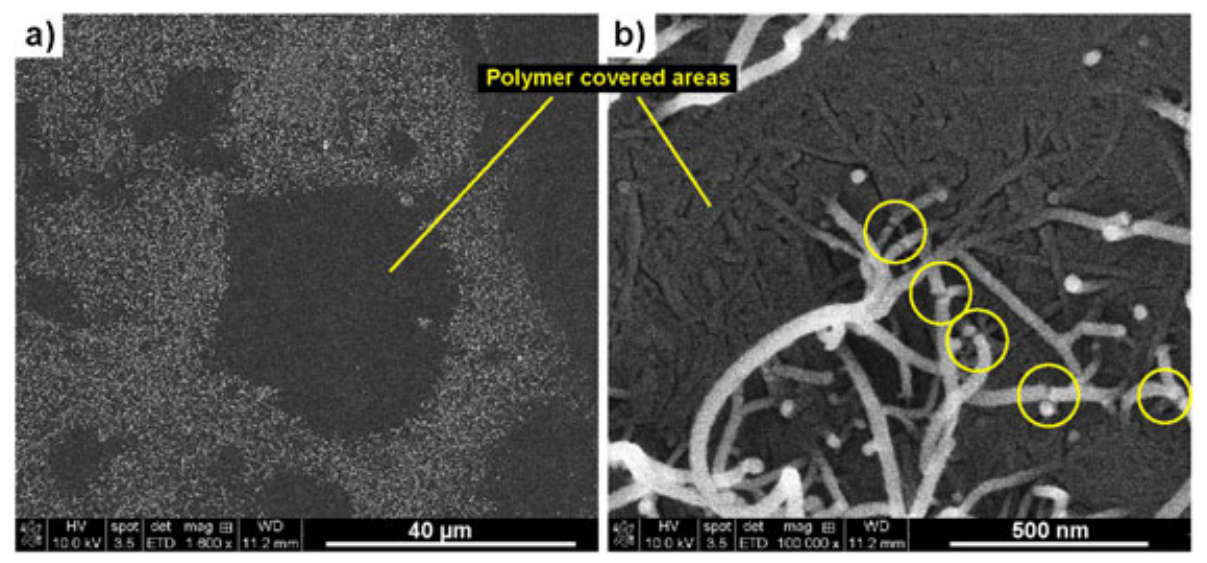

Figure 2. Scanning electron microscope image of the bottom of the freestanding composite film. The sample is sputtered with gold for enhanced contrast. Overview (a) and zoom-in (b). Many ends of broken carbon nanotubes (yellow circles) can be detected. Tubes diving into the polymer can be clearly seen.
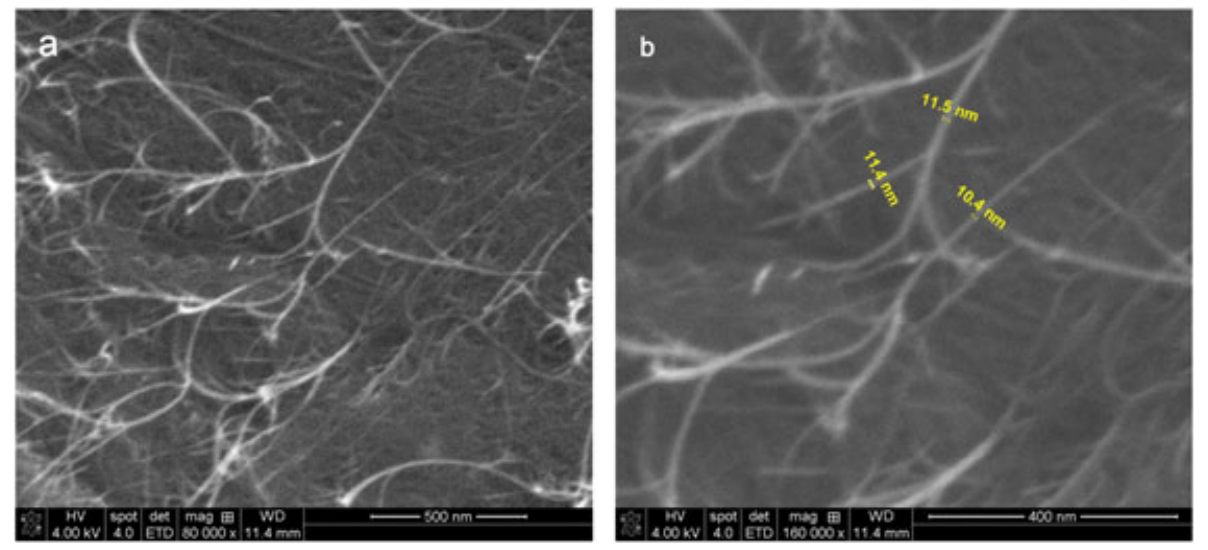

Figure 3. Scanning electron microscope image of the bottom of the freestanding composite film, without Au coating for emphasized aspect ratio. Overview (a) and zoom-in (b), showing the measurement of the diameters of the tube bundles.

component of the composite an epoxy/amine system was chosen, as this is well known to our group from previous studies (e.g. ${ }^{[24]}$ ). The SWCNT film with a thickness of $\sim 40 \mathrm{~nm}$ was prepared on a glass substrate, followed by the addition of excess polymer mixture on top (with a thickness of $\sim 60 \mu \mathrm{m}$ ) and cross-linking of the polymer matrix. The freestanding film was subsequently peeledoff the glass substrate, and all TERS measurements were carried out at the bottom side of the film. If we examine the bottom of our sample with a SEM, we can discriminate between regions fully covered by polymer and regions where SWCNTs are sticking out of the polymer (Fig. 2a). Among the SWCNTs sticking out of the polymer, we can see disrupted CNTs (Fig. 2b), indicating that excessive strain is implied to the tubes during the peeling-off process. Some embedded CNTs that are close to the surface can be seen, but with low contrast, so we tried a TERM of the sample to obtain further information about the CNTs beneath the polymer layer. The low contrast mentioned for the SEM images refers to the SWCNTs under a thin polymer layer. This can be most clearly seen from locations where the tubes dive into the polymer layer, showing that the contrast is gradually lost.

To check the diameter of the SWCNT bundles, SEM images of an uncoated sample were also taken. Figure 3 shows a SEM image of the bottom of the freestanding composite film, without Au coating for emphasized aspect ratio. Figure $3 a$ shows an overview and Fig. $3 \mathrm{~b}$ a zoom-in on the sample, illustrating the measurement of the diameters of the tube bundles. We measured the diameter of

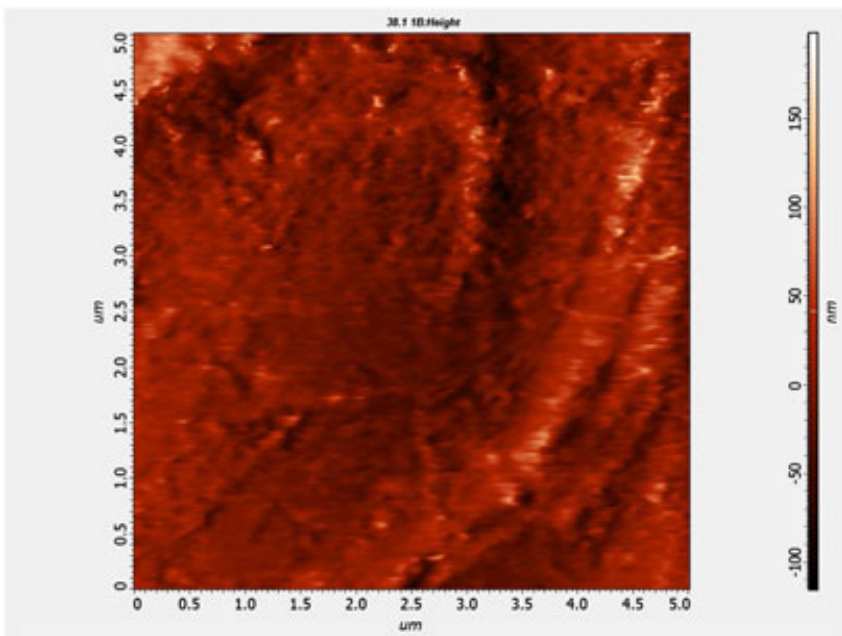

Figure 4. Atomic force microscopy height image of the bottom of the freestanding composite film, polymer covered area.

the bundles to be between 10 and $12 \mathrm{~nm}$. A gold coating on all sides changes the diameter of the bundles to $\sim 50 \mathrm{~nm}$. In both cases, these ropes of aligned tubes split into smaller diameter ones before diving into the polymer, suggesting that the tubes tend to form these ropes at the surface of the sample for increased stability. 
Tuning fork

Sample on glass support

$\rightarrow$ Gold tip $\longleftrightarrow$ Scan directions microscope objective $\mathrm{NA}=1.3$

\section{Raman spectrum to detector

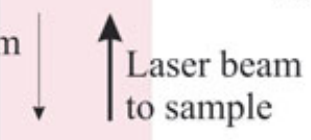

Figure 5. Experimental tip-enhanced Raman spectroscopy setup for transparent samples. A laser beam (from below) is focused by a high numerical aperture objective on the sample. In the center of the focus, a sharp gold tip, attached to a vibrating tuning fork, is placed. The distance of the tip is kept constant by a feedback loop to a piezoelectric actuator, and the mapping is carried out by a high-precision XY-stage. The Raman spectrum is collected by a microscope objective with high numerical aperture (NA 1.3) and fed into the spectrometer.
Figure 4 shows an atomic force microscopy (AFM) height image of the material used. From this image, it is clear that AFM cannot image SWCNTs under a thin polymer layer.

The typical setup of a TERS experiment on a transparent sample can be seen in Fig. 5. Our sample is placed on the sample stage of an inverted optical microscope. The stage can be finely moved by piezoelectric actuators in $x$-direction and $y$-direction, covering an area of $50 \mu \mathrm{m} \times 50 \mu \mathrm{m}$. The sample stage's drift during the long measurement times is compensated by applying capacitive feedback to the piezoelectric actuators. The shear-force head of an AFM is placed over the sample stage, equipped with a quartz tuning fork. A self-etched gold tip glued to the tuning fork with a tip radius of approximately 20 to $30 \mathrm{~nm}$ radius is held at a constant distance to the samples surface by applying feedback of the vibrational amplitude signal to a piezoelectric actuator. Using the $100 \times$ oil immersion objective of the microscope with its high numerical aperture of 1.3, a laser beam is focused onto the tip. The tipenhanced Raman spectrum of the sample is then collected by the same objective and fed to a Raman spectrometer. A total of $256 \times 256$ pixels were measured with a Raman signal
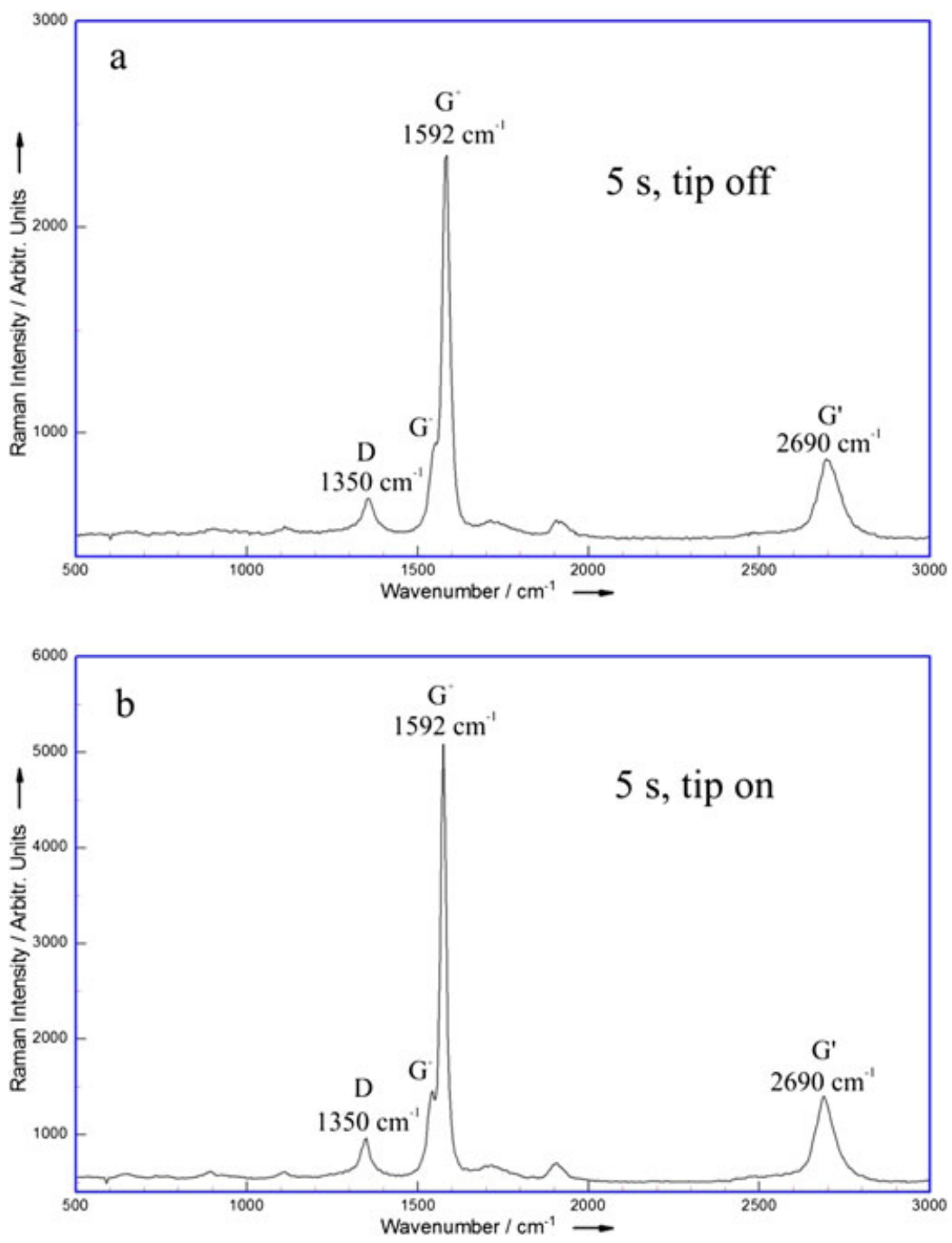

Figure 6. Confocal (a) and tip-enhanced (b) Raman spectrum of a single-walled carbon nanotube network embedded in an epoxy/amine polymer. Enhancement for the $\mathrm{G}^{+}$-line: 4600 counts $/ 1900$ counts $=\sim 2.4$. 

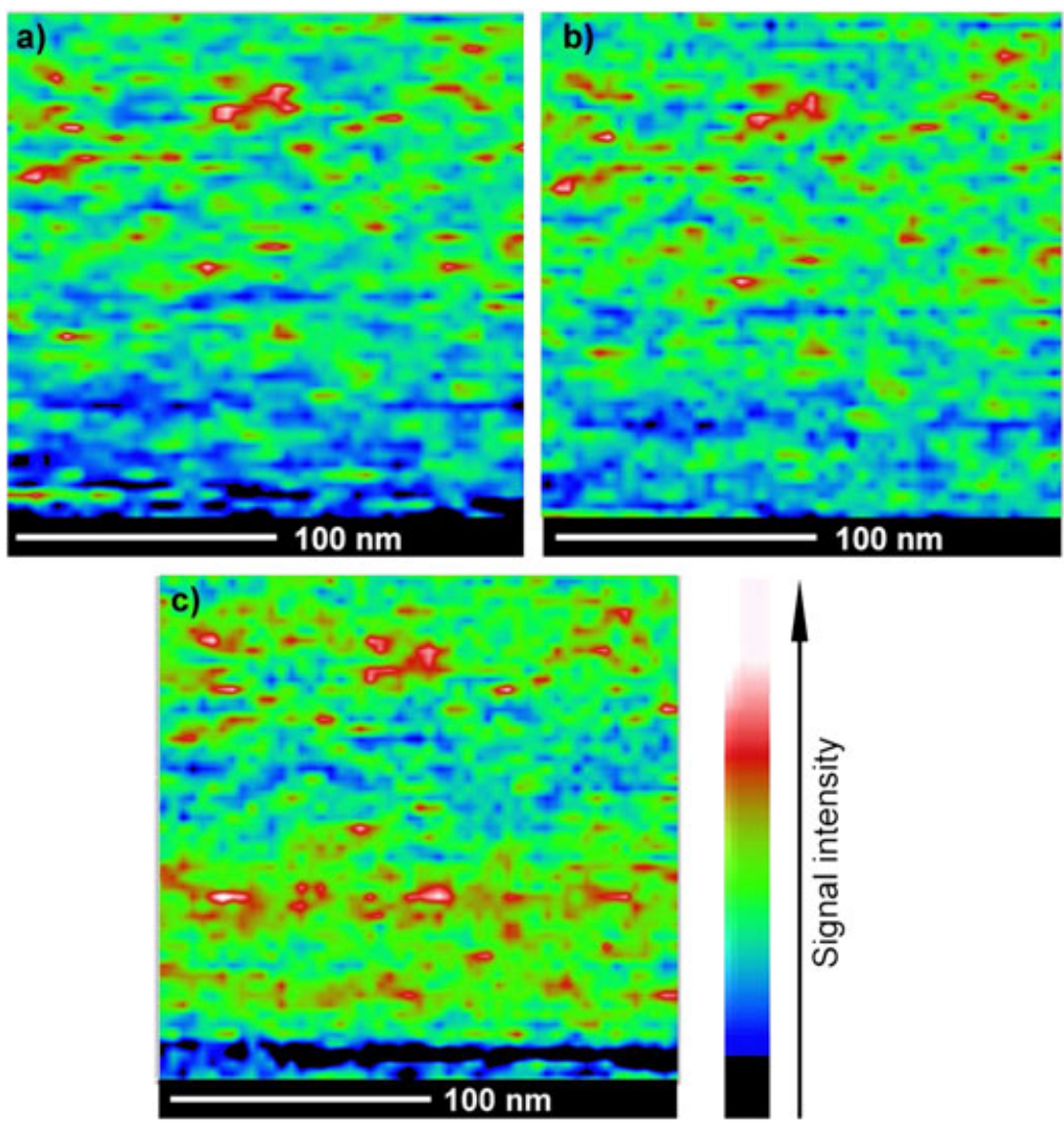

Figure 7. Tip-enhanced Raman mapping of a single-walled carbon nanotube network embedded in an epoxy/amine polymer. (a) $\mathrm{G}^{+}$-line, (b) $\mathrm{G}^{\prime}-$ line, and (c) D-line. The areas of maximal intensity (coded in white) correspond to (a) 4200 counts, (b) 1300 counts, and (c) 830 counts, respectively.

collection time of $5 \mathrm{~s}$ per pixel. A low laser power of $100 \mu \mathrm{W}$ was used for the TER mapping.

Although TERS is in principle a surface method, in the case of SWCNTs, we can measure through a thin polymer layer. This is due to the penetration of the near-field inside the polymer and the very intense resonance Raman signals of the tubes and the enhancement effect of the gold tip reaching a few nanometer into the transparent polymer.

As the spectrum of the SWCNTs is a resonance Raman spectrum with intense bands, they will obscure the polymer bands of much lesser intensity, and hence information about the polymer is difficult or impossible to extract.

Figure 6 shows the Raman spectra of our sample, which were used to calculate the enhancement: Spectrum a shows the confocal Raman spectrum without gold tip (far field), whereas spectrum b shows the Raman spectrum with the tip landed (near field and far field). The enhancement factor depends on several factors, such as laser spot size and tip radius, but here, the ratio of the line intensity in spectrum $b$ to the line intensity in spectrum $a$ is taken as the enhancement. The enhancement of the $\mathrm{G}^{+}$-line is only $\sim 2.4$, compared with $\sim 250$ as formerly reported by $\mathrm{us}^{[20]}$ for pristine SWCNTs. The low enhancement also serves as a proof that we really measured the polymer-embedded part of the sample's nanotubes, as the non-covered tubes should show a much higher enhancement, as previously reported. The tip-enhanced Raman maps using the $\mathrm{G}^{+}$-line (a), G'-line (b), and D-line (c) are shown in Fig. 7. An area of $200 \mathrm{~nm} \times 200 \mathrm{~nm}$ has been mapped, where a dense network of SWCNTs can be seen. The mapped area shows a homogeneous distribution of the CNTs in the composite material. This suggests that the polymer impregnation process does not lead to CNT agglomeration and that the final composite material does not contain segregation of the two components.

Whether a sample is homogeneous or not is a matter of scale. The TERS maps show the homogeneity on the nanoscale, while the homogeneity on a larger scale can be judged from the SEM images. From the SEM images, the overall homogeneity is judged to be rather good, but, of course, locally, as can be seen from the TERS images, defects and other variations in morphology do occur.

The ratio of the D- ('defect') line to the $\mathrm{G}^{+}$-line (as a measure of the amount of nanotubes present) is used as an indicator of damage. Whereas the ratio of $\mathrm{D}$ to $\mathrm{G}^{+}$-line is approximately constant in the upper half of the mapping, it is much higher in the lower half. The intensities have been normalized to the strongest intensity of the appropriate line, so that the areas of maximal intensity (coded in white) correspond to (a) $\mathrm{G}^{+}$-line: 4200 counts, (b) G'-line: 1300 counts, and (c) D-line: 830 counts. The SWCNT/polymer-films have to be peeled-off from the glass substrate, and, as the epoxy polymer is a very good adhesive, this cannot be done without exerting mechanical stress to the sample. Hence, some damage is expected to occur to the nanotubes. We conclude from the line ratios that Fig. 6 shows the TERM of an area of the sample that is largely undamaged in the upper half, but apparently has experienced some damaging stress during the peel-off process in the lower half. Because the whole area is covered in polymer, the 'visual' detection of structural damage due to stress inside this composite material would be impossible. 


\section{Conclusion}

In general, the properties of a polymer can be largely improved by adding CNTs resulting in nanocomposites with high thermal and electrical conductivity that also show extraordinary mechanical strength (see, e.g. Ma and Zhang ${ }^{[26]}$ and references cited therein). However, the embedding prevents the examination of the CNT network within the polymer composite by electron microscopic methods. We used TERS and TERM for this purpose. While SEM imaging was used to 'visualize' SWCNTs sticking out of a polymer composite material, TERS was used to map the first layer of a polymer-embedded conductive network of SWCNTs underneath a layer of pure polymer for the first time. Results show that impregnating an existing SWCNT network with a polymer does not lead to phase separation, as it appears from SEM images.

Moreover, using the ratio of the D- ('defect') line to the $\mathrm{G}^{+}$-line in the SWCNTs tip-enhanced Raman spectrum, we succeeded in detecting damage caused to the network's tubes by mechanical stress. This means that subjecting a composite sample to mechanical stress leads to tube-breaking inside the polymer matrix that also damages the CNTs' and deteriorates the composite's electrical properties. Our results show that TERM can be used to successfully identify and characterize the structural integrity of the SWCNTs underneath a layer of pure polymer and provides valuable information about homogeneity and stress-effects for a polymer composite.

\section{Acknowledgements}

This research forms part of the research program of the Dutch Polymer Institute (DPI), project \#756 (CoCoCo).

\section{References}

[1] W. Marx, A. Barth, Phys. Status Solidi B-Basic Solid State Physics 2008, 245, 2347.

[2] J. Z. Kovacs, B. S. Velagala, K. Schulte, W. Bauhofer, Compos. Sci. Technol. 2007, 67, 922.

[3] M. B. Bryning, M. F. Islam, J. M. Kikkawa, A. G. Yodh, Adv. Mater. 2005, 17, 1186.
[4] J. Sandler, M. S. P. Shaffer, T. Prasse, W. Bauhofer, K. Schulte, A. H. Windle, Polymer 1999, 40, 5967.

[5] O. A. Bârsan, G. G. Hoffmann, L. G. J. van der Ven, G. de With, Faraday Discuss. 2014, 173, 365.

[6] R. M. Stöckle, Y. D. Suh, V. Deckert, R. Zenobi, Chem. Phys.Lett. 2000, 318, 131.

[7] Y. Okuno, Y. Saito, P. Verma, Phys. Rev. Lett. 2013, 111.

[8] M. Ghislandi, G. G. Hoffmann, E. Tkalya, L. J. Xue, G. de With, Appl. Spectrosc. Rev. 2012, 47, 371.

[9] X. Wang, D. Zhang, K. Braun, H. J. Egelhaaf, C. J. Brabec, A. J. Meixner, Adv. Funct. Mater. 2010, 20, 492.

[10] E. M. van Schrojenstein Lantman, T. Deckert-Gaudig, A. J. Mank, V. Deckert, B. M. Weckhuysen, Nat. Nanotechnol. 2012, 7, 583.

[11] R. D. Hartschuh, N. Lee, D. Mehtani, A. Kisliuk, M. D. Foster, A. P. Sokolov, J. F. Maguire, Plasmonics: Nanoimaging, Nanofabrication, and their Applications II 2006, 6324, N3240.

[12] L. J. Xue, W. Z. Li, G. G. Hoffmann, J. G. P. Goossens, J. Loos, G. de With, Macromolecules 2011, 44, 2852.

[13] R. Bohme, M. Richter, D. Cialla, P. Rosch, V. Deckert, J. Popp, J. Raman Spectrosc. 2009, 40, 1452.

[14] E. Lipiec, R. Sekine, J. Bielecki, W. M. Kwiatek, B. R. Wood, Angew Chem. Int. Ed. 2014, 53, 169.

[15] T. Deckert-Gaudig, E. Bailo, V. Deckert, Phys. Chem. Chem. Phys. 2009, $11,7360$.

[16] D. Kurouski, T. Deckert-Gaudig, V. Deckert, I. K. Lednev, Biophys. J. 2014 106, 263.

[17] R. Böhme, M. Mkandawire, U. Krause-Buchholz, P. Rosch, G. Rodel, J. Popp, V. Deckert, Chem. Commun. 2011, 47, 11453.

[18] D. Cialla, T. Deckert-Gaudig, C. Budich, M. Laue, R. Moller, D. Naumann, V. Deckert, J. Popp, J. Raman Spectrosc. 2009, 40, 240.

[19] N. Hayazawa, M. Motohashi, Y. Saito, S. Kawata, Nanosensing: Materials, Devices, and Systems lii 2007, 6769, P7690.

[20] S. S. Kharintsev, G. G. Hoffmann, P. S. Dorozhkin, G. de With, J. Loos, Nanotechnology 2007, 18.

[21] B. Ren, G. Picardi, B. Pettinger, Rev.Sci. Instrum. 2004, 75, 837.

[22] B. S. Yeo, E. Amstad, T. Schmid, J. Stadler, R. Zenobi, Small 2009, 5, 952.

[23] X. Li, F. Gittleson, M. Carmo, R. C. Sekol, A. D. Taylor, ACS Nano 2012, 6, 1347.

[24] N. N. A. H. Meis, L. G. J. van der Ven, R. A. T. M. van Benthem, G. de With, Prog. Org. Coat. 2014, 77, 176.

[25] M. S. Dresselhaus, G. Dresselhaus, R. Saito, A. Jorio, Phys. Rep.- Rev. Sec. Phys. Lett. 2005, 409, 47.

[26] P. C. Ma, Y. Zhang, Renew. Sus. Energ. Rev. 2014, 30, 651. 